\title{
Learning and Work in the Lives of Young Adults \\ Rachel Brooks
}

\section{Published in the International Journal of Lifelong Education, 2006}

\section{Introduction}

As numerous commentators have recognised, the vast literature on 'lifelong learning' suggests that the term has been understood in very different, and sometimes conflicting, ways by policymakers, educationalists and members of the public. Some understandings are clearly predicated upon economic arguments - that individuals continually need to update their skills in order to participate in the 'knowledge economy' and enhance the competitiveness of their nation. Others emphasise, instead, the personal value of lifelong learning: the need to develop throughout one's lifetime to cope with increasingly rapid social change and maximise personal fulfilment. Arguments have also been made about the increasing commodification of education and training, and the role of lifelong learning in facilitating personal consumption of important positional goods. Thirdly, the social contribution of lifelong learning is emphasised - by those who argue for its value in promoting active citizenship and increasing democratic participation. Despite an apparent difference of emphasis, many of these definitions share a common concern with social well-being whether that is through an individual's capacity to support him/herself and his/her community economically, develop personally or engage more actively in wider society. However, this view is not uncontentious. Indeed, Tight (1998) argues that 
lifelong learning can be seen as a form of social control, while Coffield (1999) notes that, "we are clearly not dealing with an unambiguous, neutral or static concept, but one which is currently being fought over by numerous interest groups, all struggling for their definition' (p.488).

Research has explored the extent to which these different meanings are shared by those who have engaged in 'lifelong learning' and also by those who have decided against taking up such opportunities. However, these studies have, invariably, focused on older people and/or those who left formal education at an early age. As a result, there have been few studies that have explored in any depth the experiences of young adults in their 20 s, who have recently graduated from university. In part, this can be explained by the relatively privileged status of this group of young adults (in terms of both their educational history and likely social class position) and perhaps a tacit assumption that they are the least in need of encouragement to pursue further learning. However, as a result of the mass expansion of the higher education sector over recent years, graduates are likely to constitute an increasingly significant proportion of the labour force. It would, therefore, seem timely to investigate their attitudes to education and training in the future.

It is also clear that, for this age group, the balance between learning, work and leisure has shifted considerably over recent decades. Many young people now work throughout the whole of their post-compulsory education, entering the labour market well before any higher education applications have been made, and continue to work throughout their time at university (Callender and Kemp, 2000). In part, this may be driven by: young people's desires to maintain a particular 'consumer lifestyle' (Miles, 
2000); shifts towards flexible labour in many sectors of the economy that have provided more opportunities for student employment (Canny, 2002); as well as the increasing costs of studying for a degree. Within this context, many young people have become very practised at 'juggling' a job, an education and a social life. This paper explores whether this experience of combining education and employment may facilitate lifelong learning, through the 'normalisation' of these patterns or whether, conversely, the financial pressures that many young people experience during their post-compulsory education act as a disincentive to pursue further learning. In doing so, the paper interrogates the three versions of a 'learning society' outlined by Edwards (1997). It explores whether the learning pursued by young adults can best be seen as part of: the liberal democratic project of responding to social change and furthering citizenship; the 'learning market' model, whereby individuals seek to respond to the changing demands of the market; or a post-modern conceptualisation of the learning society, in which individuals and groups engage in learning to further their own heterogeneous goals.

\section{Research Methods}

This paper draws on a series of life history interviews, conducted with thirty adults in their mid- to late-20s who, in most cases, had completed their first degree in 1998. As the fieldwork for this project took place between October 2003 and February 2004, for most respondents, five years had elapsed since they graduated. A 'realist' approach to the life history interview was adopted; the young graduates were asked to

\footnotetext{
${ }^{1}$ This draws on the typology developed by Miller (2000). He distinguishes between a 'realist' approach to life history interviews, based on an inductive approach to data collection and analysis, a 'neopositivist' approach, with deduction at its core, and a 'narrative' approach which places primary emphasis on the development of the respondent's view during the telling of the life history.
} 
tell the story (or stories) of their 'learning experiences' from their earliest memories onwards. In addition, they were asked about a number of other topics including their experiences of paid work throughout their lives, their engagement with any voluntary or extra-curricular activities, and their leisure pursuits.

Respondents were recruited through alumni websites and magazines of two different higher education institutions, as well as through an advert on 'Friends Reunited' website. Fifteen had attended 'Old University', an institution founded in the 1950s, which is commonly found in the 'top 20' of national league tables. The other fifteen had attended 'New University': a higher education institution in the same geographical area as 'Old University', but one which frequently occupies a position near the bottom of most league tables. As Tables 1 and 2 demonstrate, those who offered to take part in the research were not necessary typical of all graduates. Indeed, half the sample had pursued postgraduate level study and all respondents claimed that they had taken part in some form of learning since graduation. (This compares to a national figure of only 50 per cent (Pollard et al., 2004).) It is also likely that this method of selecting respondents skewed the sample towards those who considered themselves to be relatively successful in terms of their employment: few had experienced periods of unemployment since graduating and, as can be seen from Tables 1 and 2, almost all were employed in broadly 'professional' jobs. The sample was not intended to be statistically representative, nor was it large enough to cover all variables that might have some bearing on attitudes to and experiences of lifelong learning. Nonetheless, the diversity in terms of family background, subject of first degree and type of employment enabled a reasonably broad range of graduate experience to be explored. It should be noted, however, that although several of the 
respondents were co-habiting with partners, only one had any children. As previous research has indicated (for example, Hewison et al., 2000), families can often act as a constraint on uptake of lifelong learning - especially for women - and thus the patterns identified here may not be replicated amongst young graduates with more familial responsibilities.

[Insert Tables 1 and 2]

In the life history interviews, respondents were left to define their 'learning experiences' in any ways they wanted; there was no assumption that they would be confined to learning within specialist institutions. However, the majority of the graduates focussed primarily on their learning experiences at school, college and then university. Although a small number did talk about the learning they had done at home and at work in the period up until graduation (indeed, this is explored further below), in the narratives of most of the young graduates, clear conceptual distinctions were made between education, work and leisure, and learning tended to be associated with only the first of these. It was only when they talked about their learning experiences since graduation that many respondents described non-institutional learning - for example, at work, through self-study at home, and through their daily activities. Even here, however, there was a tendency to equate learning with formal study. As a result, the focus of this paper is largely on the ways in which the young graduates did, or did not, combine work with formal study (pursued either on their own or in educational institutions or training centres) and relatively little time is spent exploring experiences of workplace learning. In many ways, this could be considered a serious omission, as learning 'on the job' is clearly an important way in which all 
workers, whether graduates or not, can further their own development and enhance their ability to do a job - through interactions with colleagues, undertaking specific tasks and playing their work roles (Fuller and Unwin, 2005). Nevertheless, the focus on more formal approaches to learning remains closer to the respondents' own understandings.

\section{Learning and work at school, college and university}

\section{Patterns of participation}

A large majority of the young adults who took part in this research had worked during their time at school, college and university, as Table 3 demonstrates. Engaging in paid work during this period of their lives was thus common across the sample as a whole, despite considerable differences in the family background and social class of respondents. However, subsumed under this overall pattern are important differences; the implications of working during university holidays only would seem to be quite different from those associated with significant levels of term time work.

[Insert Table 3]

This pattern of part-time working appears to be typical of those identified by other studies in the UK (e.g. Broadbridge and Swanson, 2005; Callender and Kemp, 2000) as well as other European countries (Hodgson and Spours, 2001). A majority of the sixth-formers in Elsheikh and Leney's (2002) research had a part-time job and, the authors argue, part-time working was an embedded part of their culture. In the three studies discussed by Hodgson and Spours (2001), between 70 and 80 per cent of their 
sample of 16-19 year olds was working on a regular basis - not just at weekends or the holidays. Indeed, such was the strong expectation of part-time work that a teacher who was interviewed as part of the research commented:

It is patently obvious that part-time employment is now the absolute norm for sixth form students in this school. It is as much an ingrained part of their lives as their academic work or their social activities. Those who do not work largely see themselves as deviating from this norm and are frequently embarrassed by the fact. (p.380)

Drawing on OECD figures, Mizen (2003) shows how, between 1984 and 1995 the percentage of young men in the UK combining education and employment rose from 15 to 22 per cent, while the comparable figure for young women jumped from 18 to 33 per cent. It has been argued that these increases are in part related to: increases in demand for paid, flexible labour within the UK over this period (Canny, 2002); continued economic growth, particularly in the service sector; new expensive objects of youth consumption; and the increased likelihood of incurring debt at university (Hodgson and Spours, 2001). In theorising these trends, du Bois Reymond (1998) has suggested that the tendency to combine work and learning (alongside a similar tendency to combine work and leisure time) has resulted in increasingly more complex concepts of life - which have gained wide cultural acceptance.

These patterns are commonly sustained once young people reach university (Universities UK, 2003). Indeed, research from the Institute of Employment Studies (Pollard et al., 2004) has indicated that 42 per cent of the undergraduates who applied 
to university in 1998 worked during term time and around 90 per cent of undergraduates are now thought to take paid work at some point during their studies. Similarly, in research conducted amongst first-year undergraduates at the University of Teeside (Nutt, 2005), more than half the sample was employed for between ten and twenty five hours of paid work alongside their full-time studies (and for many this reflected patterns that had been established during their sixth-form studies). Amongst Pollard et al.'s respondents, those who worked during term-time (rather than only during university holidays) were more likely to be from poorer backgrounds (a finding which also emerged from Hunt et al's (2004) study of undergraduates at Northumbria University). Nevertheless, Mizen suggests that part-time work for young people may well be the preserve of the more affluent, giving them an advantage when competing for jobs later on in their lives. This is a theme pursued in more detail later in the paper.

\section{Reasons for combining work and study}

Despite their differing social backgrounds, when asked about their reason for taking up paid employment during their studies, few of the graduates involved in this research stated that it had been necessary to fund their studies; it appeared that in only one or two cases had part-time work been necessary to finance accommodation or other living costs, for example. Instead, across the sample as a whole, respondents outlined three main reasons for engaging in part-time work. Firstly, several claimed that their work had been primarily to fund what they perceived to be the 'student lifestyle'. Ben (post-doctoral researcher) was typical: 
I just liked the money. I could buy computers, mountain bikes, that sort of stuff.....I started earning money and I didn't want to drop down in the money I earned, so I could just live to the standards I had become accustomed to!

For these students, consumption and socialising were both central elements of a student identity and, as such, could only be afforded through part-time work. Moreover, one graduate explained how taking on a job that brought her into contact with several other students - as her colleagues - helped her to integrate socially into her new student lifestyle. In many ways this reflects the conclusions Elsheikh and Leney (2002) drew from their study of sixth-formers' working patterns. They argue that, for the majority of their respondents, paid work allowed them independence, purchasing power and social confidence - as well as the opportunity to take on an adult role. Similarly, Lucas (1997) has suggested that, for some young people, work can operate as a paid social life; paid work provides the legitimation for what would otherwise be a social activity.

Secondly, five of the thirty young graduates involved in this research claimed that one of the reasons why they engaged in paid employment at university was because they had more free time than they had been used to when they were at school and/or college:

I thought that I would have to put a lot more effort in [to my degree] because A Level history was a thousand times more difficult than my degree. [So] I was able to have part-time jobs and not worry about having to do essays and things. (Leila, teacher) 
I worked in a café all the way through uni....By the end of my time there I was working more in the café than at college. I only needed to go in ten minutes a week for the course and half an hour for my dissertation. So the rest of the time I was at home with a cup of tea or at the café. (Clare, production assistant, animation company)

This is an issue addressed by Nutt (2005) in relation to her study of undergraduates' paid work in Teeside. She suggests that part of the reason why her respondents worked such long hours during their first degree at university was because of the relatively small number of contact hours they had on their courses and a failure to recognise the importance of independent study. This, she contends, is related to the non-traditional status of the students in her sample: as none had parents who had gone on to higher education, they were unaware of the importance of ongoing independent study throughout the three or four years of their degree. However, amongst the five graduates from Old and New University who claimed that they had worked because of the relatively light demands of their degree courses, were two with familial experience of HE. Furthermore, several of them also claimed that they had pursued their degree studies diligently. Indeed, Leila who went on to study for a Master's degree had been quite surprised at how little free time she had as a postgraduate, when compared to her experience as an undergraduate.

Thirdly, the most frequently cited reason for engaging in part-time employment during university - but also, for some, at school and/or college as well - was to enhance their employability when they entered the graduate labour market, on 
completion of their degree. Underpinning many of the young adults' narratives was an assumption that no longer was there a clear and automatic correspondence between the achievement of a degree and fulfilling, graduate-level employment. In their analysis of the Australian education system, Dwyer and Wyn (2001) argue that as a result of the massification of higher education and the encouragement of high aspirations, many graduates come to assume a one-to-one relationship between acquisition of a degree and a fulfilling professional career. They go on to argue that, as a result of these assumptions, many young people are acutely disappointed when they seek full-time employment on completion of their higher education. However, amongst this sample of young adults, there was a clearly articulated belief that a degree, alone, was insufficient to secure a professional job. Relevant work experience was seen as key to achieving desired destinations within the labour market. Nick (audio producer) was typical of many when he claimed:

You can pass your English degree, you can pass whatever degree, but without doing extra things while at university, it's not really worth that much....with a bit of effort you might get a job, but you'll be far down the ladder compared to someone who's gone out and done something.

Part-time work was also seen as offering several more specific labour market advantages. Several respondents believed that they had had the opportunity to develop particular work-related skills. The most frequently mentioned of these was confidence at dealing with other people: 
Then I worked myself up to assistant bar manager by the time I got onto my $\mathrm{PhD}$....And it was quite good - it improved my confidence immensely....you see other people and it builds you confidence, dealing with people, teaching people. You get used to different ways of teaching people.....and that came in handy when I was teaching physics. (Ben, post-doctoral researcher)

In addition, they described the employment networks that they had accessed through their part-time work, and the contacts that they had established that had, in several cases, led directly to offers of employment:

Over the first summer I did office work for a temping agency and they really liked me and asked me to stay on. I said I didn't want to do accounts and could I do marketing and they said OK. So then I did that part-time for the last two years of my degree and then they employed me afterwards and gave me my big career break: they paid me a good salary and transferred me to London. (Lisa, web designer and marketing executive)

Furthermore, many of the young graduates explained how they had taken up part-time jobs partly to find out more about the world of work and the kind of jobs that might appeal to them in the future, when they were in a position to seek full-time employment:

I worked for a local firm of actuaries [in the summer holidays]...It was actually very good experience. I think it taught me quite a lot of things about 
the working environment and it kind of convinced me that I would be happy working in an office (Tim, actuary)

[I chose to become a solicitor] mainly because of the work I did, I think. Because I really didn't know much about law other than the very general perception of what it was as a subject. But working was fascinating because I worked in a personal injury department...it was to do with stories, in a way people giving their side of events - so yeah, I thought, there's quite a lot of interest there. (Richard, solicitor)

In all these areas, respondents believed that their education, alone, would not have offered adequate preparation, thus replicating the findings of several other studies (see, for example, Martin et al., 2000).

In many ways, these young people had much in common with the 'Players' in Brown and Hesketh's (2004) study of graduate recruitment practices. In their analysis, 'Players' were those graduates who understood employability as a positional game and typically took steps 'to market themselves in ways that conformed to the requirements of employers in order to win a competitive advantage' (p.9). This frequently included such practices as using social contacts to find out what employers were looking for, reading books on how to answer difficult interview questions and attending workshops that simulated group exercises at assessment centres. In contrast, 'Purists' viewed graduate recruitment as a meritocratic race, in which their aim was to find employment that offered the right 'fit' with their skills and qualifications. Brown and Hesketh contend that, despite credential inflation, 
academic qualifications are no longer enough to secure employment within the graduate labour market. Instead, graduates are expected to be able to draw on a range of extra-curricular activities relevant to the workplace. Moreover, this needs to be 'packaged as a narrative of employability' to be sold to employers. In this way, one's experience has to be 'worked at' as 'a reflexive project of the self where the things one does and how they are understood is captured in terms of individual employability rather than intrinsic human experience' (p.220). Few 'Purists' were evident among the thirty young graduates involved in this project. Indeed, many described how they had been acutely aware of the need to develop a range of relevant work-related skills - and how this had, at least in part, underpinned their decision to take on part-time work.

\section{Perceived impact on education and employment}

To date, most discussions of students engaging in paid work during their studies have concentrated on the harmful effects of such pursuits on academic attainment. For example, Pollard et al. (2004) claim that, amongst university students, working during term time had more impact on students' degree results than any other factor. In their sample, 58 per cent of those who worked regularly gained a first or upper second, compared to 71 per cent who did not take paid jobs, and similar results have emerged from more local studies of specific higher education institutions (Hunt et al., 2004; Nutt, 2005). (However, it is interesting to note that working during university holidays only was associated with higher levels of academic attainment.) Amongst the young graduates involved in this research, there was also some recognition of the negative impact that engagement in paid work had on their studies. Two young 
women believed that their attendance in class had been adversely affected by their paid work, while another four respondents (all male), believed that the time they had been able to devote to their university work had been significantly curtailed by their term-time employment. Nevertheless, most of these respondents claimed that these disadvantages were offset by longer-term benefits:

During the last six months [of working and studying for a degree] it just became utter hell...My dissertation could have been a lot better. It was pretty much the bare minimum... but the last two years were a bit of a means to an end. I was just trying to get as much experience in to beef up my $\mathrm{CV}$, because in any media career you need to have that extra curricular activity on the CV. (Nick, audio producer)

Moreover, in response to a neutral interview question, asking them about the effect they thought their paid work had had on their academic studies, the majority of the graduates specified a number of benefits that they believed accrued from their parttime work. As discussed above, four respondents claimed that their paid work had enabled them to integrate more fully with other students - either because they were colleagues (as noted above) or because their earnings enabled them to participate in more social activities. While clearly few policy-makers or educationalists would argue that a university's raison d'etre is to facilitate new modes of sociality, social integration is believed to be an important element of ensuring student retention (Tinto, 1994) and may thus have a positive impact on academic progress. Secondly, and in contrast, others claimed that if they had not have been working they would have been socialising and, thus, their academic work benefited as a result. For example, John 
explained that his part-time job at a cinema allowed him to make good progress through the reading list for his course, while Megan's work as a waitress for one night a week ensured that she had 'a clear head' to get on with her studies the following morning.

Several students explained that their part-time work had motivated them to persevere with their degrees to ensure that they could secure better jobs on graduation, while others pointed to the transferable skills that they had gained in the workplace that they drew upon in their academic work. Many respondents believed that their timemanagement skills had improved, while Lorna and India both claimed that the responsibility they had gained at work had enabled them to pursue their studies in a more independent manner. More specifically, several respondents explained how their paid work had provided them with a new perspective on their academic studies (a theme that is also pursued in studies by Broadbridge and Swanson's (2005) study). For example, Lisa described how her work in an office had allowed her to see how some of the concepts she covered in her marketing degree could be applied in practice. Finally, a few graduates believed that their paid work had given their life more of a 'balance' than they would have otherwise been able to achieve at university, as India explained:

I think at times within academia it's very easy to get very enclosed. And I felt it was really important to have an aspect of my life that was just practical really - not that studying isn't functional - but more instant than that, I guess. 
The idea that a balanced life is one with both work and study in it is perhaps a further indication of the embedded nature of paid employment within young people's lives and the normalisation of work in late modern society.

Thus, the evidence from these young graduates would suggest that, despite reasonably strong evidence that working during term-time has a negative impact on attainment, students do not always share this view. One possible interpretation of this is that the respondents were, retrospectively, providing a positive slant on what, at the time, was financial necessity. Nevertheless, the neutrality of the questioning (I did not ask them about any 'advantages' of part-time work, for example, nor imply that I thought termtime working was good or bad) and the detailed nature of some of their replies suggest that they did indeed believe that their employment had benefited their academic work, at least in some measure. Furthermore, the wider literature on the graduate labour market would suggest that while term-time employment may depress final degree results, it does not necessarily have an equally damaging effect on future career prospects. Indeed, Pollard et al. (2004) found that most of their respondents who were in full-time employment believed that their work experience at university had helped them to secure a job, while the graduates without relevant work experience (gained as a paid employee or in a voluntary capacity) in Pitcher and Purcell's (1998) study had experienced difficulty in gaining graduate-level employment.

It is also the case that a small number of other studies have highlighted a "perception gap' between students, on the one hand, and teachers and other educationalists on the other. For example, in their analysis of part-time work amongst 16-19 year old students, Hodgson and Spours (2001) claim that while many teachers see part-time 
work as part of 'a disturbing phenomenon' where study does not always come first when earning and learning conflict, students are more positive about their ability to do both. Indeed, Hodgson and Spours suggest that the capacity to combine both work and study differs from individual to individual, and that students can construct different relationships between study and part-time work. To interrogate this further, they develop a typology of student approaches to work. Of those who try to combine work and study, they identify: 'balancers' (those who manage to work without it affecting their study and who usually limit the number of hours they work each week); 'risk-takers' (who ignore advice about the impact of long hours on work); and 'connectors' (who make active connections between their part-time work and fulltime course). Certainly within this study no respondents expressed any regret about the decisions they had made to engage in paid work during their time at school, college and/or university and several believed that their work had been key to securing full-time employment on graduation. The following section of the paper explores the extent to which these patterns were maintained in the young adults' postuniversity lives.

\section{Learning and work in post-university lives}

\section{Evidence of continuity}

From the interviews with the young adults it emerged that few saw the end of their time at university as signalling the end of their education, and thus appeared not to subscribe to the idea of a front-loaded education system. Indeed, as I have shown elsewhere (Brooks, forthcoming), all respondents believed that they had engaged in 
some form of learning since completing their first degree, while a third of the sample had gone on to formal postgraduate study. At the beginning of this paper, I speculated that the increased cost of studying for a degree and the increasing size of average student debt on completion of a first degree (DfES, 2005), may be making young people less inclined to pursue further study in the years immediately after graduation. However, on the basis of this sample, there was little evidence of financial pressures acting as a disincentive to further learning. Indeed, in some cases the opposite appeared to be true: Carl described how he had used his periods of unemployment to study for qualifications in IT, to boost his CV. In many ways, this reflects du Bois Reymond's (1998) contention that young professionals often see unemployment as 'extra time for learning and living' (p.71) during which they can continue their education and development.

Thus, it is possible that the patterns of combining work and study, set for some at university and for others at a much earlier date, may have become normalised by the time the young adults graduated. For example, several respondents - from both Old University and New University - spoke of strong and important continuities in the balance of their lives before and after university. Indeed, Annie claimed that she had enjoyed the university lifestyle so much that she had resisted taking on a full-time job on completion of her degree, to allow her to continue to take up new learning opportunities, travel and socialise with friends:

Initially I just wanted to locum [as a social worker], so I wasn't tied to anything.....so that gave me a three and a half day week so I did other things 
during the week - I did some [voluntary] work at a centre for homeless people, did some IT courses - and enjoyed my weekends.

Although this decision to work part-time did not seem to have been taken by anyone else in the sample, Try (2004) has shown how flexible working (here defined as taking up a part-time or temporary job) increased considerably amongst Norwegian graduates between 1985 until 1999. Indeed, Try shows how over this period more than half of graduates entered employment through a flexible job, and argues that this growth in part-time work appears to have a voluntary basis: increasing numbers stated that further education - and the desire to keep studying after university - was the main reason for working part-time. He concludes that 'flexible jobs may result from a deliberate choice among graduates, either because these jobs are regarded as a good investment opportunity, or because they represent freedom and flexibility for the individual worker..... what may represent a career trap for low qualified workers could still make up a possibility for the higher educated' (p.43). Similarly, in their study of young people across Europe, Lewis et al. (2002) have argued that the better qualified and those in the early stages of their career paths often viewed temporary jobs positively. Furthermore, Lewis (2003) has contended that amongst the young and highly educated there is a growing trend towards integrating different aspects of life. She maintains that we need to move on from conceptualising the worker as passive and reactive, to a more dynamic model, which recognises the increasingly boundaryless nature of much contemporary work. This is a theme taken up by Brown and Hesketh (2004) who argue that a characteristic of post-industrial societies is the importance attached to personal achievement and self-actualization. As a consequence of this, 'the issue is not only one of how to make a living, even a good 
one, but finding work that is a source of personal interest, satisfaction, learning and growth' (p.227).

\section{Evidence of change}

Across the sample as a whole, despite the high degree of continuity between patterns of combining work and study before and after graduation, there were also some important differences that were highlighted by the respondents. Although some commentators have argued that the majority of undergraduates in British universities are now part-time students by virtue of the long hours they spend in paid employment, most respondents in this study claimed that the balance between work and study had shifted considerably when they had entered the labour market as a full-time worker after their degree.

About half the sample felt that combining work and study had become much more difficult, because of the demands of their job and the hours they were required to work. Furthermore, several felt that they had had less autonomy and freedom in their learning since leaving university because of the geographical and temporal constraints placed on their choice of learning provider and the need they felt to follow very vocationally-relevant courses. In contrast, however, others believed that combining work and study had become easier since completing their degrees. For example, in contrast to Lewis' (2003) argument, discussed above, about the increasingly blurred boundaries between work and other aspects on lives, Nick believed that it was an increasing clarity to such boundaries that had motivated him to take up further learning (courses in web design and Indian head massage) once he had started 
working full-time. Others believed that since leaving university they had been able to take more control of their own learning, partly as a result of having more discretion over how they spent their time:

I manage my own time, anyway, because I run my own business so I can sort of fit things in as much as I want. (Steve, director of family marketing company)

I do feel that the research environment allows me to do this [taking time off to study] and not worry too much about it. I think the idea of taking a morning off at work would be madness to many people. Here no one bats an eyelid. (Peter, scientific researcher)

To a large extent, these differences are explained by the sector of employment and/or type of organization in which a respondent worked. This reflects findings from other studies that have emphasised the importance of specific organizational cultures to the facilitation of lifelong learning. Fuller and Unwin (2005) note that 'it is the way new opportunities for learning are embedded, supported and managed within a wider context of workforce development that will determine the extent to which they are utilized for productive learning, or will be resisted or subverted by employees' (p.36).

Differences to patterns of combining work and study were also related to changes in the respondents' social networks since leaving university. While numerous studies have highlighted the way in which women's ability to participate in educational programmes is often determined by their relationships within the home (for example, 
Heenan, 2002; Gouthro, 2005), peer relationships also appeared to have considerable impact on respondents' sense of ease at engaging with further learning. In this quotation, Jane explains how she found balancing work and study harder, as a result of changing expectations on behalf of both her friends and her partner:

The struggle to do some work on a Sunday afternoon, rather than go to the pub, is still there...The difference is, when you're at university, all your friends are saying 'I've got to go and do my work now', whereas when you're a graduate none of your friends are saying 'I can't go down the pub'. Everybody wants you to go down the pub and says 'Don't worry, you'll be fine.' It's hard to say, 'No, I won't, I've got to do this.'

However, this was not replicated across the sample as a whole. Indeed, in the cases where a respondent's social network was composed largely of his or her colleagues, or others in a similar area of work, then there was evidence that they could act as a strong support of post-university learning. Tim, for example, described how most of his friends were studying for the same actuarial qualifications as him and, thus, like him 'only want[ed] a social life out of the exam times'.

\section{'Employability' as a key motivator}

While there clearly are important differences between experiences of combining paid work and formal learning before and after graduation (not least because of the shift from full-time student to full-time employee), the respondents' narratives suggested a strong degree of continuity in the motivation for maintaining such patterns. In 
discussing the decision made by Annie, above, I suggested that an individual's desire to maintain more of an equal balance between different activities could underpin a decision to continue with formal study. However, it is also possible that incentives to maintain such patterns emanated, not from the young adults themselves and their desire to both work and learn, but from wider social pressures. In particular, across the sample as a whole, the decision to engage in formal study post-graduation appeared to be underpinned by a desire to further one's 'employability'. For example, many respondents described how they had engaged in further education or training outside their full-time jobs as a way of maintaining or enhancing their labour market flexibility, and placing themselves in the strongest position to apply for their next job. Jason's comment is typical:

With the amount of people going [to university] it is diluting the effects, the influence that it has. A lot of it now is supplementary voluntary work, learning outside of work, just trying to develop yourself continually throughout the course of your lifetime really. You can't really be content to sit back and carry on with life the way it is if you want to excel.

In part, this appeared to be driven by what Brown and Hesketh (2004) have termed 'positional conflict'. They maintain that employment is not based on an assessment of the fit between an individual's level of qualification and experience and that required by the job. Instead, it is determined through a highly competitive comparison with others where, as a result of the over-supply of graduate labour, not everyone can win, even if all contestants are equally well qualified. 
The young adults' narratives also suggested that they had internalised many of the messages about the importance of self-reliance, enterprise and flexibility that have been argued to underpin the concept of 'lifelong learning' (Edwards, 2002; Griffin, 1999) and to determine attitudes to work (du Gay, 1996). Indeed, writing specifically about young people and lifelong learning, du Bois Reymond has argued that welleducated and socially privileged young people (the 'Trendsetters' in her research project) strove to redefine the constraints created by flexibilization and rationalization of labour and the requirements of lifelong learning by incorporating their personal lives into their working lives (p.67). It is these kinds of considerations that seemed to be driving some of the young adults in the sample. Megan, for example, spoke of her constant concern that all the activities she pursued outside work enabled her to learn new skills (and thus were 'CV-able'):

I'm actually quite conscious now that anything I do out of work I actually want to be beneficial to my CV now....I know that I'm in a position now where there are lots of people with similar experience so I've got to start doing stuff that makes me look sharper than the next person for the next job.

\section{Conclusion}

In many ways it can be argued that all workers engage in important forms of learning, as they take on new jobs or assume new roles within the workplace. Indeed, in his overview of current trends in lifelong learning, Evans (2003) argues that learning has become a personal activity for individuals as never before, covering an 
unprecedentedly wide range of topics. Nevertheless, he goes on to contend that perhaps the most important aspect of all this is that most people would not describe what they are doing as learning as they seek to master whatever topic they engage with (within the workplace, at home or in many other settings). He thus points to a tension between the way people are leading their lives and the government's emphasis on formal institutions as the primary means of boosting lifelong learning. However, this paper has placed the focus firmly on more formal types of learning. In part, this relates to the ways in which respondents, themselves, conceptualised learning, as discussed above: the majority tended to associate lifelong learning in their postuniversity lives with formal study - whether pursued at home, at work or within an educational institution. It is also related to the aim of exploring continuities and discontinuities in patterns of combining work and learning and, more specifically, the extent to which experiences of combining formal education and paid work while at school, college and university facilitate or, conversely, militate against the maintenance of these patterns post-graduation, during early adulthood.

The evidence from the thirty young graduates, discussed in this paper, has suggested that there are clearly some negative consequences to working long hours during one's schooling and higher education. Nonetheless, it appears that some of the potential benefits of combining activities in this way have been overlooked by previous studies. Many of these are strongly related to the competitive nature of the graduate labour market. Within this analysis, it could be argued that young people, employers and society as a whole would benefit if students felt less need to supplement their studies with paid employment (and could thus devote more time to their studies). However, the evidence from the young graduates involved in this research, as well as from other 
studies, suggests that as a result of the way in which the labour market is currently structured and the high level of competition for jobs that are deemed 'professional', relevant work experience is an important means of differentiating oneself from other graduates. As Brown (1997) has argued, the massification of higher education has altered the mechanism through which the middle classes secure their positional advantage; no longer is a degree sufficient to gain access to professional, middle class employment. Instead, he suggests that emphasis is now placed on the 'charismatic personality' and a range of work-related skills, gained from activities pursued outside the formal curriculum of schools, colleges and universities. Moreover, the respondents' narratives strongly suggested that they had internalised the government's perspective on the relationship between higher education and the economy: very few saw higher education as primarily a time for intellectual development and growth. Instead, it was conceived of as a period of preparation for full labour market involvement. In this way, significant periods of paid work were not seen as inimical to the aims of university but - in contrast - broadly in line with them. Indeed, both were viewed primarily as a means of furthering one's employability within a competitive graduate labour market. It was also the case that many respondents thought that their paid work had had a number of positive and direct benefits on their higher education studies such as: enabling them to integrate more fully with other students; providing motivation to persevere with their academic work; and helping them to achieve a healthy balance between different types of activity.

This emphasis on combining different types of activity seemed to be something that was important to most of the young adults in their lives after graduation, as well. Indeed, on the basis of this sample there was scant evidence that debt incurred as a 
student or other financial pressures had deterred respondents for engaging in further learning. On the contrary, there appeared to be strong continuities between the way in which the graduates had combined work, study and, in most cases, leisure in their lives before and after graduation. However, this is clearly not the same as positing a causal relationship between the two: it is not necessarily the case that it was the experience of juggling work and study at school and/or university that caused or enabled graduates to maintain such patterns post-graduation. Indeed, just as I have suggested above that concerns about employability had an important bearing on young people's decisions to take up paid employment during their degree (and earlier), so many respondents' choices to continue to combine work and formal study post-graduation appears to have been driven, at least partially, by ongoing insecurities about labour market position. du Bois Reymond (1998) has argued that the extent to which young adults are able to combine different parts of their lives (such as work, leisure and learning) is related to their social location, with it being much easier for the more privileged, who are typically engaged in more fulfilling forms of work. Although all the young adults in this project were graduates and thus obviously more highly educated than many of their peers, there were, nevertheless, important differences in their social position (in terms of their familial background, the type of university they had attended, and the status of their job at the time of interview, or example). Nevertheless, across all of these groups there appeared to be a strong belief that further formal learning was important, not only to maintain one's flexibility at work, but also to try to achieve 'an edge' over others.

Thus, while there were certainly some differences in the ways in which the young graduates combined paid work and formal learning pre- and post-graduation (for 
example, in the time that was devoted to the two activities and the differing levels of available social support), these were outweighed by the important continuities. Most significantly, respondents' understandings of the purpose of study throughout their time at school and college and into their post-university lives appeared to be firmly tied to notions of employability. This understanding facilitated both engagement in paid work during periods of full-time study, and the take up of further formal study while in full-time employment. Indeed, there was little evidence of personal development or home and family concerns motivating learning, in the ways outlined by Merriam and Clark (1991) in their study of the interrelationships between work, love and learning. In contrast, the young adults involved in this study appeared to understand learning primarily as means of preparing for, and securing advantage within, the labour market.

The continuities in these understandings, from school, through college and university, and on into post-university life, suggest that they were based on long-held values. While there is not sufficient evidence to determine, on an individual basis, the source of these values, the privileging of notions of 'employability' across the sample, suggests the widespread nature of such values, across different social groups. Writing in 2000, Coffield was able to identify ten differing models of a learning society. Nevertheless, he concluded that: 'For over twenty years the skills growth model allied to a learning market has constituted the dominant discourse, sweeping all criticism before it' (p.28). While it can be argued that New Labour has introduced a new variant of this model, placing much greater emphasis on tackling social exclusion, the centrality of employment to social reform has been maintained. Thus, throughout most of the respondents' lives, dominant conceptualisations of a 'learning society' 
have undergone little change. It is therefore perhaps unsurprising that this study provides no evidence to suggest that Edwards' (1997) second model of a 'learning society' - one which foregrounds the performativity of education, training and other forms of learning - has become outdated. Indeed, amongst the large majority of young graduates involved in this study, learning was closely tied to achieving, and then sustaining, individual competitiveness within the labour market.

\section{Acknowledgements}

I am very grateful to the thirty young graduates who gave up considerable amounts of time to tell me their life histories, and to the Nuffield Foundation for funding this research.

\section{References}

Du BOIS REYMOND, M. (1998) 'I Don't Want to Commit Myself Yet': Young People's Life Concepts, Journal of Youth Studies 1 (1), 63-79.

BROADBRIDGE, A. and SWANSON, V. (2005) Earning and Learning: how termtime employment impacts on students' adjustments to university life, Journal of Education and Work, 18 (2), 235-249.

BROOKS, R. (forthcoming) Young Graduates and Lifelong Learning: the impact of institutional stratification, Sociology. 
BROWN, P. (1997) Cultural Capital and Social Exclusion: Some Observations on Recent Trends in Education, Employment and the Labour Market, in HALSEY, A.H, LAUDER, H., BROWN, P. and WELLS, A. (Eds) Education, Culture, Economy, Society Oxford: Oxford University Press.

BROWN, P. and HESKETH, A. (2004) The Mismanagement of Talent. Employability and Jobs in the Knowledge Economy Oxford, Oxford University Press.

CALLENDER, C. and KEMP, M. (2000) Changing Student Finances: income, expenditure and the take-up of student loans among full- and part-time higher education students in 1998/99 Research Report RR213 London, Department for Education and Employment.

CANNY, A. (2002) Flexible labour? The growth of student employment in the UK, Journal of Education and Work, 15 (3), 277-301.

COFFIELD, F. (1999) Breaking the consensus: lifelong learning as social control, British Educational Research Journal, 25 (4), 479-500.

COFFIELD, F. (2000) A critical analysis of the concept of a learning society, in: COFFIELD, F. (ed) Differing Visions of a Learning Society Bristol, The Policy Press.

DEPARTMENT FOR EDUCATION AND SKILLS (2005) Trends in Education and Skills http://www.dfes.gov.uk/trends (Accessed 28 June 2005). 
DWYER, P. and WYN, J. (2001) Youth, Education and Risk. Facing the Future London: RoutledgeFalmer.

EDWARDS, R. (1997) Changing Places? Flexibility, Lifelong Learning and a Learning Society London, Routledge.

EDWARDS, R. (2002) Mobilizing Lifelong Learning: governmentality in educational practices, Journal of Education Policy, 17 (3), 353-365.

ELSHEIKH, E. and LENEY, T. (2002) Work, Work, Work! Students' perceptions of study and work-life balance under Curriculum 2000 London, Association of Teachers and Lecturers.

EVANS, N. (2003) Making Sense of Lifelong Learning. Respecting the Needs of All London, RoutledgeFalmer.

FULLER, A. and UNWIN, L. (2005) Older and Wiser?: workplace learning from the perspective of experienced employees, International Journal of Lifelong Education, $24(1), 21-40$.

Du GAY, P. (1995) Consumption and Identity at Work London, Sage.

GOUTHRO, P. (2005) A critical feminist analysis of the homeplace as a learning site: expanding the discourse of lifelong learning, International Journal of Lifelong Education, 24 (1), 5-20. 
GRIFFIN, C. (1999) Lifelong Learning and Welfare Reform, International Journal of Lifelong Education, 18 (6), 431-452.

HEENAN, D. (2002) Women, access and progression: an examination of women's reasons for not continuing in higher education following the completion of a certificate in women's studies, Studies in Continuing Education, 24 (1), 39-55.

HEWISON, J., DOWSWELL, T and MILLAR, B. (2000) Changing patterns of training provision in the National Health Service: an overview, in: COFFIELD, F. (ed) Differing Visions of a Learning Society Bristol, The Policy Press.

HODGSON, A. and SPOURS, K. (2001) Part-time Work and Full-time Education in the UK: the emergence of a curriculum and policy issue, Journal of Education and Work, 14 (3), 373-388.

HUNT, A., LINCOLN, I. and WALKER, A. (2004) Term-time employment and academic attainment: evidence from a large-scale survey of undergraduates at Northumbria University, Journal of Further and Higher Education, 28 (1), 3-18.

LEWIS, S., SMITHSON, J. and KUGELBERG, C. (2002) Into Work. Job Insecurity and Changing Psychological Contracts, in: BRANNEN, J., LEWIS, S., NILSEN, A. and SMITHSON, J. (2002) Young Europeans, Work and Family. Futures in Transition London, Routledge. 
LEWIS, S. (2003) The integration of paid work and the rest of life. Is post-industrial work the new leisure? Leisure Studies, 22, 343-355.

LUCAS, R. (1997) Youth, Gender and Part-Time Work: students in the labour process, Work, Employment and Society, 11 (4), 595-614.

MARTIN, A., MILNE-HOME, J., BARRETT, J., SPALDING, E. and JONES, G. (2000) Graduate Satisfaction with University and Perceived Employment Preparation, Journal of Education and Work, 13 (2), 199-213.

MERRIAM, S. and CLARK, M.C. (1991) Lifelines: Patterns of Work, Love and Learning in Adulthood California, Jossey-Bass Publishers.

MILES, S. (2000) Youth Lifestyles in a Changing World Buckingham, Open University Press.

MILLER, R. (2000) Researching Life Stories and Family Histories London, Sage.

MIZEN, P. (2003) The Changing State of Youth Basingstoke, Palgrave.

NUTT, D. (2005) Work Now - Pay Later: first generation students' aspirations versus reality. Paper presented to the Social Diversity and Higher Education Seminar, University of Wolverhampton, February 2005. 
PITCHER, J. and PURCELL, K. (1998) Diverse Expectations and Access to Opportunities: is there a graduate labour market? Higher Education Quarterly, 52 (2), 179-203.

POLLARD, E., PEARSON, R. and WILLISON, R. (2004) Next Choices: career choices beyond university Brighton, Institute for Employment Studies.

TIGHT, M. (1998) Lifelong learning: opportunity or compulsion? British Journal of Educational Studies, 46 (3), 251-263.

TINTO, V. (1994) Leaving College. Rethinking the Causes and Cures of Student Attrition Chicago, University of Chicago Press.

TRY, S. (2004) The role of flexible work in the transition from higher education into the labour market, Journal of Education and Work, 17 (1), 27-45.

UNIVERSITIES UK (2003) Attitudes to Debt. School leavers and further education students' attitudes to debt and their impact on participation in higher education London, Universities UK. 